\title{
Academies seek better prospects for postdocs
}

Jessica Ebert, Washington

The US National Institutes of Health (NIH) is being urged to introduce a set of reforms to improve the lot of postdocs and increase their chances of establishing independent scientific careers.

A report from a National Academies panel chaired by Thomas Cech, president of the Howard Hughes Medical Institute in Chevy Chase, Maryland, says that postdoctoral training should be limited to five years.

The 18 March report also says that postdoc training grants should be made available to non-US citizens, and that money should be transferred from the NIH's main funding mechanism to support independent research awards that would enable postdocs to pursue their own projects.

Cech says that, if implemented, the recommendations will "encourage young investigators to take on top-rate, important projects, to deviate from the research of their previous mentors, and to strike out in new directions, tackle new systems and develop new methods".

The study also suggests that the NIH should introduce a class of investigator grant specifically tailored to help young scientists moving into their first posts as independent investigators. It recommends awarding 200 of them annually, worth $\$ 500,000$ each over five years.

"The current NIH grant system really honours safe research in well-established pathways," Cech claims. "We want to break away from that and find mechanisms that will free up researchers in the early stages of

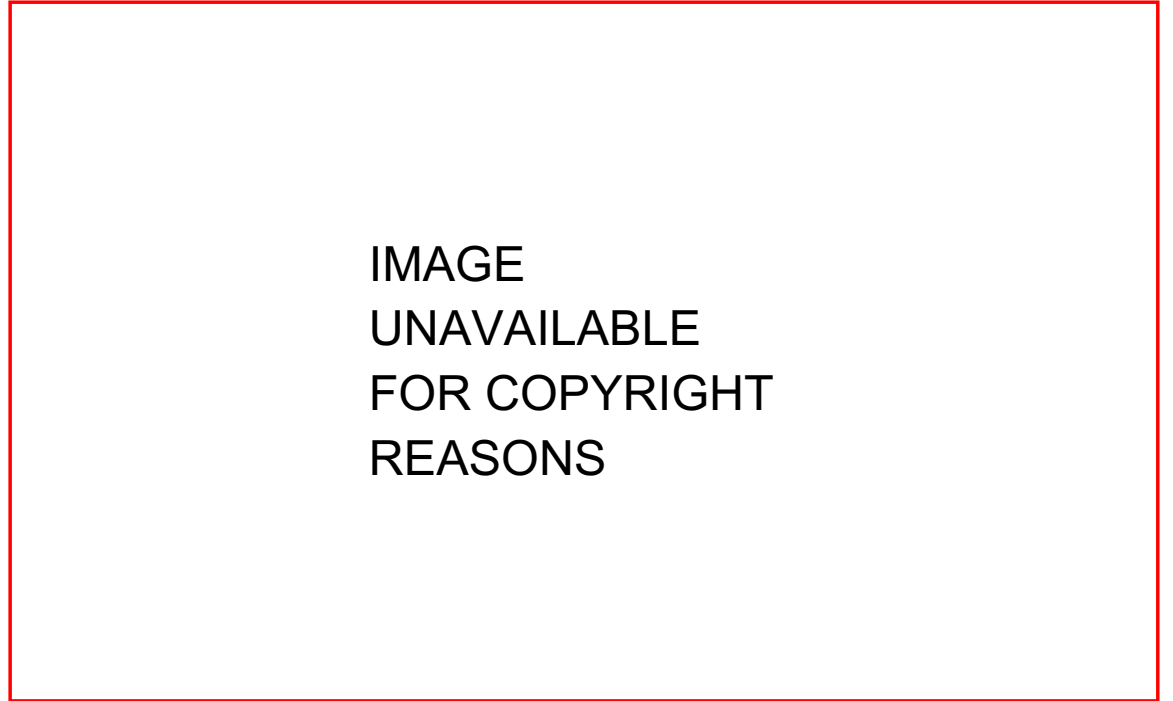

Rocky road: many US postdocs find that their chosen career path can be tough going.

their career to make the big discoveries that are really going to have an impact on medicine and on human health."

Last June, NIH director Elias Zerhouni asked the National Academies to look into mechanisms that would enhance postdoctoral training and foster young researchers' independence.

Zerhouni says that some of the committee's recommendations — such as that requiring senior researchers to describe in their grant applications what they would do to nurture their postdocs' careers could be implemented relatively quickly. He notes that a steering committee to deal with the other recommendations has already been set up.

The report was requested after it emerged that the NIH budget is increasingly going to fund older, established researchers. Between 1980 and 2003, for example, the percentage of grants going to researchers aged under 40 fell from more than a half to less than one-fifth.

"We've come up with recommendations that are evolutionary, not revolutionary," says Cech, who hopes this will make it easier for the NIH to implement them. "The vitality of the biomedical sciences in the United States depends on taking some action soon," he adds.

\section{US undervalues foreign researchers, survey reveals}

Rex Dalton, San Diego

Foreign postdocs in the United States work longer hours and publish more, but are paid less than their American counterparts, according to a poll of young scientists.

The survey, by Sigma Xi, a scientific research society in Research Triangle Park, North Carolina, also found that substantial numbers of foreign postdocs experience some form of visa or international travel problems because of US security rules.

But a preliminary version of the analysis, which was released on 11 March at the third annual meeting of the National Postdoctoral Association in San Diego, did contain some encouraging results. Male and female postdocs are paid about the same, it indicated, and stipends have risen steadily over the past decade. "That is pretty good news," says mathematician Geoff Davis, who led the survey.
The questionnaire gauged the views of 7,500 postdocs at nearly 50 universities or research institutions. It was sent to 22,000 postdocs - about $40 \%$ of the total thought to be working in the United States.

The median salary for all respondents was $\$ 38,000$ per year - up from $\$ 28,000$ in 1995. On average, electrical engineers fared best, earning about $\$ 45,000$, and ecologists came off worst with $\$ 35,600$.

The median for foreign postdocs was $\$ 37,000-8 \%$ less than the $\$ 40,000$ received

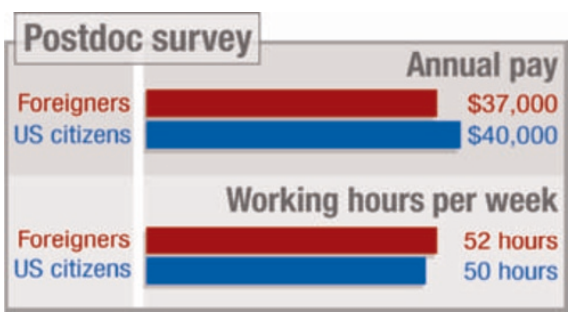

by US citizens. But the foreign scientists said that they worked 52 hours a week two hours more than the Americans. And international postdocs said that they had produced almost $30 \%$ more peer-reviewed, published articles than their American counterparts.

Nearly three-fifths of the foreign researchers reported experiencing difficulties on re-entering the United States after travelling abroad.

The survey, which is published in full in American Scientist next month, comes at a time when US universities and research agencies are making increasing efforts to address the lot of postdocs (see above). Faced with postdoc organizations springing up on campus, many universities are appointing administrators to operate offices dedicated to them. But postdocs continue to complain of long hours and uncertain career prospects. 